\title{
EL REDENTOR DEL ASTERION DE BORGES
}

\author{
POR \\ DONALD McGRADY \\ University of Virginia
}

Entre las frondosas páginas de la bibliografía sobre Borges parece que todavía falta un estudio de su actitud hacia la religión. Claro está que la visión negativa del escritor de los grandes cultos consta en frases tan tajantes como las siguientes:

Israelitas, cristianos y musulmanes profesan la inmortalidad, pero la veneración que tributan al primer siglo [= el mundo] prueba que sólo

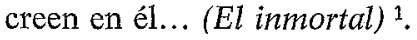

Aaron Loewenthal... era muy religioso; creía tener con el Señor un pacto secreto, que lo eximía de obrar bien, a trueque de oraciones y devociones (Emma $Z$ Zunz) ${ }^{2}$.

Quizás este crimen pertenece a la historia de las supersticiones jutdías... Como el cristianismo... (La muerte y la brúiula) ${ }^{3}$.

Cuando se haga el análisis de la postura de Borges ante las creencias religiosas habrá que explicar también por qué son judíos tantos de sus personajes -en Emma Zunz, por citar un solo caso, todos lo son, menos el marinero nórdico que le quita su virginidad a la protagonista.

Sean las que sean las causas de esta conocida antipatía de Borges hacia el judaísmo y el cristianismo, aquéllas no se basan en la ignorancia. Su fascinación con la cábala, por ejemplo, es archisabida por todos. Pero hay otros indicios del profundo interés de Borges en las religiones de Occidente, tales como se reflejan en sus lecturas de los libros canónicos. Aquí

\footnotetext{
${ }^{1}$ En Nueva antología personal (Buenos Aires: Emecé, 1968), p. 166.

${ }^{2}$ En Nueva antología personal, p. 127.

${ }^{3}$ En Ficciones (Buenos Aires: Emecé, 1963), p. 145.
} 
voy a señalar un caso en que una oscura cita bíblica ayuda a aclarar el sentido de un cuento.

Hace ya un buen cuarto de siglo que Enrique Anderson Imbert estudió magistralmente en las páginas de esta revista La casa de Asterión, uno de los relatos más ingeniosos del maestro ${ }^{4}$. Allí destacó Anderson Imbert que en esta narración Borges sigue su técnica favorita de jugar con el lector, proponiéndole (sin aviso previo, naturalmente) un misterio que se disuelve al final. En La casa de Asterión el misterio consiste en identificar al narrador, el Minotauro. Borges describe el laberinto de Creta y la vida de su monstruo desde el punto de vista de éste, y esto constituye su principal estratagema para despistar al lector, ya que «no se nos ocurre que una bestia pueda tener un 'yo' narrativo» (Anderson, p. 39). También advierte nuestro crítico que el mismo Borges afirma en el epílogo de $E l$ Aleph que «a una tela de Watts, pintada en 1896, debo La casa de Asterión y el carácter del pobre protagonista». Según Anderson Imbert, Borges «se instaló con simpatía, con compasión dentro del monstruo» (p. 40), y esto se ve en el adjetivo pobre. En el cuadro de Watts, Borges vio al Minotauro «solitario, en lo alto de un parapeto de su laberinto, soñador, melancólico, contemplando el mar y como esperando. ¿Esperando qué?». Y contesta Anderson: «Esperando a su redentor... el Minotauro... cree que el redentor le traerá amor y lo sacará de su laberinto... el Minotauro espera un redentor amigo» (p. 40). Por esto, casi no se defiende cuando Teseo le hunde su espada. Más adelante recuerda Anderson Imbert que, «para Borges, el mundo es caos, y dentro del caos, el hombre está perdido como en un laberinto» (p. 41), y concluye con la idea de que la angustia expresada por el monstruo es la misma que siente el autor en su universo $\mathrm{y}$, en fin, «Borges es Asterión, el Minotauro» (p. 43).

Confieso que aun cuando siempre he admirado mucho este estudio de Anderson Imbert, no me satisfacía su conclusión final, la identificación de Borges en su mundo caótico con el Minotauro en su laberinto. Me parecía más bien que el cuento era sencillamente un rompecabezas cuyo objeto era descifrar quién era el narrador. Pero el descubrimiento de una cita bíblica hacia lo último del relato me ha persuadido de que Anderson tiene razón al ver este segundo nivel de referencia en el protagonista. Sin embargo, el redentor tan ansiosamente anhelado por el Minotauro no será un amigo que lo saque de su laberinto para llevarlo a conocer otros am-

${ }^{4}$ «Un cuento de Borges: La casa de Asterión», RI, 25 (1960), 33-43; reimpreso en Crítica interna (Madrid: Taurus, 1961), pp. 247-259. Aquí utilizo la primera versión y a ella remiten los números de las páginas citadas en el texto. Anderson reproduce el cuento en sus pp. 34-35. 
bientes de este mundo nuestro (Asterión quisiera ir a «un lugar con menos galerías y menos puertas»).

Hay dos alusiones bíblicas en La casa de Asterión, y creo que en ellas se oculta el secreto del verdadero sentido de esta narración (la cual es, como todas las de Borges, más profunda de lo que parece a primera - -y aun a segunda - vista). Ambas citas religiosas figuran en el último párrafo referido por Asterión. La primera de ellas dice: «Cada nueve años entran en la casa nueve hombres para que yo los libre de todo mal.» Explica Anderson Imbert (p. 39) que se trata de las nueve víctimas atenienses enviadas por el rey Minos al Minotauro periódicamente, y que la cláusula «los libre de todo mal» proviene del Padrenuestro, donde se reza «líbranos de todo mal» (San Mateo 6:13). Pero mientras en la oración «el mal» alude al pecado, aquí se refiere a la vida. Esto es, «para el Minotauro el mal es la vida: librar a los hombres de todo mal es un eufemismo por matarlos» (Anderson, p. 39). Habría que agregar que éste es el razonamiento que yace debajo de la acción de todo el cuento y que explica su desenlace, donde Asterión se entrega mansamente a la espada de Teseo: es que para él -igual que para sus víctimas - la vida es el mal y la muerte es un bien. (Paradójicamente, ésta era la típica creencia cristiana durante la Edad Media.)

La segunda cita bíblica ocurre hacia el final de la relación del monstruo; hablando de las víctimas que sacrifican de cuando en cuando, afirma el Minotauro:

Ignoro quiénes son, pero sé que uno de ellos profetizó, en la hora de su muerte, que alguna vez llegaría mi redentor. Desde entonces no me duele la soledad, porque sé que vive mi redentor y al fin se levantará sobre el polvo.

Resulta que las palabras que he subrayado provienen textualmente del libro de Job, capítulo 19, versículo 25, en la versión protestante de Casiodoro de Reina y Cipriano de Valera, donde se lee:

Yo sé que mi Redentor vive, y al fin se levantará sobre el polvo 5 .

${ }^{5}$ La Santa Biblia (Buenos Aires, etc., 1951); es la versión distribuida por las Sociedades Bíblicas Unidas. El cotejo con la traducción católica más difundida -la de Eloíno Nácar Fuster y Alberto Colunga (Madrid: Biblioteca de Autores Cristianos, 1973) _- esclarece la cuestión de la traducción manejada por Borges: «Porque yo sé que mi Redentor vive, y al fin se erguirá como fiador sobre el polvo.» Nótese que aquí tenemos el porque que falta en Reina y Valera, pero esto puede deberse a que la frase de Borges es compuesta y la conjunción hacía falta para unir las dos cláusulas. 
No cabe la menor duda de que Borges ha citado el texto bíblico adrede, y que lo ha hecho para decirnos algo importante. Evidentemente, la cuestión que aquí se plantea es la identidad del misterioso redentor.

Si volvemos al contexto de la cita, veremos que el que pronosticó la llegada del «redentor» era uno de los mancebos inmolados por Asterión, y que hizo su profecía «en la hora de su muerte». Resulta manifiesto que se trataría más bien de una maldición que de un pronóstico: la despechada víctima diría al Minotauro que él también había de morir algún día. Lo raro del caso es que Asterión acogiera estas palabras con alegría e ilusión, no con temor, como sería de esperar. Dicho en otros términos: el monstruo está cansado de vivir, de rondar eternamente por los confines de su laberinto; él sufre del mismo mal que «el inmortal» en el cuento epónimo, que no podía dejar de vivir, aunque buscaba anhelosamente la mortalidad por toda la tierra. El Minotauro que mira tan desoladamente el mar - símbolo corriente de la muerte- en el cuadro de G. F. Watts bien puede estar soñando con el día de su descanso definitivo. A la luz de esta posibilidad adquiere nuevo sentido la afirmación de que «hay azoteas desde las que me dejo caer, hasta ensangrentarme»; parece que el Minotauro ha querido suicidarse, pero no ha podido. El sueña con un «lugar con menos galerías y menos puertas», o sea, con un paraje diferente del laberinto que lo agobia. En fin, el «redentor» es el que le traerá a Asterión la muerte.

Según ha demostrado Anderson Imbert, el Minotauro que sufre en su laberinto corresponde a Borges, que se confunde y padece en el caos del mundo. Si deshacemos la alegoría del relato, entonces Jorge Luis Borges ansía el reposo de la muerte. Pero ¿cuál será ese «lugar con menos galerías y menos puertas» adonde él quisiera ir, y quién será el redentor que lo librará? Según las interpretaciones tradicionales más aceptadas del pasaje de Job, el redentor de éste o es Dios o Jesucristo ${ }^{6}$. ¿Será posible que Borges esté insinuando su creencia en Dios a través de su cita de la enigmática frase de Job, y que aquel «lugar con menos galerías y menos puertas» sea el Cielo cristiano? Me parece probable que así sea, pues no veo otro motivo para que se haya introducido la arcana cita de Job. Claro está que Borges había cambiado el significado de su primera referencia bíblica, haciendo que el «mal» del que hay que librarnos no sea el pecado, sino la vida. Pero ese cambio se hizo precisamente para expresar el hastío del Minotauro con su existencia, y su deseo de reposar en la muerte. En el

${ }^{6}$ The Interpreter's Bible, III (Nashville: Abingdon Press, 1954), pp. 1051-1053. El versículo siguiente (Job 19,26) apoya esta explicación: «Y después de deshecha esta mi piel, aún he de ver en mi carne a Dios.» 
caso del «redentor», Borges no introduce ninguna modificación en la aceptada exégesis del pasaje de Job, y esta interpretación bíblica cuadra perfectamente con el contexto de la declaración de Asterión.

Saco en conclusión, pues, que el redentor tan afanosamente esperado por el Minotauro no es algún amigo (la amistad es probablemente un concepto ajeno al pensar del monstruo) que lo lleve a conocer otras tierras más acogedoras (la monstruosidad de Asterión hará que lo teman y lo odien en todas partes), sino Dios, que se levantará del polvo para llevarlo a una tierra sin pesar, «un lugar con menos galerías y menos puertas». Podría parecer que esta explicación contradice las frecuentes expresiones negativas de Borges sobre las religiones organizadas, pero en realidad no hay tal contradicción: la creencia en un Dios supremo y un Más Allá no presupone ni la aceptación del enorme cuerpo de doctrinas desarrolladas por los grandes cultos durante los milenios de su existencia, ni conformidad con la mala conducta de algunos de sus practicantes. Pero sea esto como fuere, no puede caber duda de que Borges ha leído extensamente en la Biblia (en una versión protestante: su propia forma de protestar contra la Iglesia católica de su país) y que ha seleccionado una oscura y poética frase del libro de Job para decirnos algo sobre el torturado modo de pensar del desgraciado cautivo del laberinto de Creta, una criatura que parece reflejar su propia angustia en un universo cuyo sentido no entiende. 
